\title{
Interplay between glucocorticoids and tumor-infiltrating lymphocytes on the prognosis of adrenocortical carcinoma
}

\author{
Laura-Sophie Landwehr (D) , ${ }^{1}$ Barbara Altieri (D) , ${ }^{1}$ Jochen Schreiner, ${ }^{1}$ Iuliu Sbiera, ${ }^{1}$ \\ Isabel Weigand (D) , ${ }^{1}$ Matthias Kroiss (D) , ${ }^{1,2}$ Martin Fassnacht (D) , , ,2,3 \\ Silviu Sbiera (1) 1,2
}

To cite: Landwehr L-S, Altieri B, Schreiner J, et al. Interplay between glucocorticoids and tumor-infiltrating lymphocytes on the prognosis of adrenocortical carcinoma. Journal for ImmunoTherapy of Cancer 2020;8:e000469. doi:10.1136/jitc-2019-000469

- Additional material is published online only. To view please visit the journal online (http://dx.doi.org/10.1136/jitc2019-000469).

Accepted 01 April 2020

Check for updates

(c) Author(s) (or their employer(s)) 2020. Re-use permitted under CC BY-NC. No commercial re-use. See rights and permissions. Published by BMJ.

${ }^{1}$ Department of Internal Medicine I, Division of Endocrinology and Diabetes, University Hospital Würzburg, Würzburg, Germany

${ }^{2}$ Comprehensive Cancer Center Mainfranken, University of Würzburg, Würzburg, Germany ${ }^{3}$ Clinical Chemistry and Laboratory Medicine, University Hospital Würzburg, Würzburg, Germany

\section{Correspondence to Dr. Silviu Sbiera; sbiera_s@ukw.de}

Prof. Dr. Martin Fassnacht; fassnacht_m@ukw.de

\section{ABSTRACT}

Background Adrenocortical carcinoma (ACC) is a rare endocrine malignancy. Tumor-related glucocorticoid excess is present in $\sim 60 \%$ of patients and associated with particularly poor prognosis. Results of first clinical trials using immune checkpoint inhibitors were heterogeneous. Here we characterize tumor-infiltrating T lymphocytes (TILs) in ACC in association with glucocorticoids as potential explanation for resistance to immunotherapy. Methods We performed immunofluorescence analysis to visualize tumor-infiltrating $\mathrm{T}$ cells $\left(\mathrm{CD}^{+}\right)$, $\mathrm{T}$ helper cells $\left(\mathrm{CD}^{+} \mathrm{CD}^{+}\right)$, cytotoxic T cells $\left(\mathrm{CD}^{+} \mathrm{CD}^{+}\right)$and regulatory T cells (Tregs; $\mathrm{CD}^{+} \mathrm{CD}^{+}{ }^{+} \mathrm{FoxP}^{+}$) in 146 ACC tissue specimens (107 primary tumors, 16 local recurrences, 23 metastases). Quantitative data of immune cell infiltration were correlated with clinical data (including glucocorticoid excess).

Results $86.3 \%$ of ACC specimens showed tumor infiltrating T cells (7.7 cells/high power field (HPF)), including T helper (74.0\%, 6.7 cells/HPF), cytotoxic T cells (84.3\%, 5.7 cells/HPF) and Tregs (49.3\%, 0.8 cells/HPF). The number of TILs was associated with better overall survival (HR for death: $0.47,95 \% \mathrm{Cl} 0.25$ to 0.87 ), which was true for $\mathrm{CD}^{+}-$and $\mathrm{CD}^{+}$subpopulations as well. In localized, non-metastatic ACC, the favorable impact of TILS on overall and recurrence-free survival was manifested even independently of ENSAT (European Network for the Study of Adrenal Tumors) stage, resection status and Ki67 index. T helper cells were negatively correlated with glucocorticoid excess (Phi=-0.290, $\mathrm{p}=0.009$ ). Patients with glucocorticoid excess and low TILs had a particularly poor overall survival (27 vs. 121 months in patients with TILs without glucocorticoid excess).

Conclusion Glucocorticoid excess is associated with T cell depletion and unfavorable prognosis. To reactivate the immune system in ACC by checkpoint inhibitors, an inhibition of adrenal steroidogenesis might be pivotal and should be tested in prospective studies.

\section{BACKGROUND}

Adrenocortical carcinoma (ACG) is a rare aggressive endocrine malignancy with an incidence of approximately one per million inhabitants per year. ${ }^{1}$ Patients diagnosed with ACC have a dismally poor prognosis. Even after complete resection, there is a strong propensity toward local recurrences and progression of distant metastases. Median overall survival in metastatic disease is less than 15 months. Complete surgical resection is the treatment of choice in localized ACC. ${ }^{2}$ The current recommended standard care for patients in advanced disease is mitotane or the combination of etoposide, doxorubicin, cisplatin, and mitotane. ${ }^{1-6}$

Activation of antitumorous immune response with immune checkpoint inhibitors has revolutionized the therapy of many cancer entities resistant to chemotherapy. Results of the first (small) trials with immunotherapy in ACC are modest, with a median progression-free survival times of 1.8, 2.1, 2.6 and 6.75 months, respectively. ${ }^{7-10}$ However, in one study with 39 patients, disease control rate was $52 \%$ and interestingly median overall survival reached almost 25 months clearly suggesting that at least a subset of patients benefits from this therapeutic approach.

One potential cause underlying these heterogeneous and partly disappointing results may be tumorous glucocorticoid secretion. Excess of steroid hormones is present in approximately $60 \%$ of patients. Cushing's syndrome due to high glucocorticoid secretion has been associated with unfavorable prognosis even after complete resection. ${ }^{1-13}$ It is well known that glucocorticoids are immunosuppressive through regulation of circulating and tumor-infiltrating immune cells. They inhibit for instance $\mathrm{T}$ helper cells $\left(\mathrm{CD}^{+} \mathrm{CD} 4^{+}\right)$and cytotoxic T-lymphocytes (CTLs, $\mathrm{CD}^{+} \mathrm{CD}^{+}$) activation. ${ }^{14}$ Even without clinically apparent Cushing's syndrome, high intratumorous glucocorticoid concentrations may lead to a local anergy of the antitumorous immune system.

$\mathrm{CD}^{+} \mathrm{CD}^{+} \mathrm{T}$ cells are crucial for $\mathrm{T}$ cell receptor-mediated activation of the adaptive immune system by interacting with $\mathrm{MHC}$ 
class II-restricted antigen-presenting cells. Additionally, T helper cells mediate the production of antibody generating $\mathrm{B}$ lymphocytes and the activation and long-term maintenance of $\mathrm{CD}^{+} \mathrm{CD}^{+}$CTLs through secretion of cytokines and chemokines such as interferon gamma and tumor necrosis factor alpha. $\mathrm{CD}^{+} \mathrm{CD}^{+}$CTLs eradicate intracellular targets by direct cell-cell contact and ensure tumor surveillance. ${ }^{15}$ The presence of circulating and/or tumor-infiltrating $\mathrm{CD}^{+} \mathrm{CD}^{+}-$and $\mathrm{CD}^{+} \mathrm{CD}^{+}{ }^{+} \mathrm{T}$ lymphocytes (TILs) correlates with favorable outcome on patients' overall survival in various human malignancies, for example, melanoma, lung cancer or head and neck squamous cell carcinoma. ${ }^{16-18}$

In contrast, regulatory $\mathrm{T}$ cells (Tregs, $\mathrm{CD} 3^{+} \mathrm{CD} 4^{+} \mathrm{CD} 25^{+-}$ $\mathrm{FoxP}^{+}$) maintain tolerance to self-antigens and prevent autoimmunity by modulating the induction of effector $\mathrm{T}$ cells. However, they actively impede antitumor immunity contributing to tumor progression in many cancers. ${ }^{19-21}$

By re-analyzing a 'multiple omics' approach using data from The Cancer Genome Atlas (TCGA) consortium, two distinct subgroups of ACC patients were identified, one with overexpression of genes related to steroidogenesis and one with overexpression of genes related to the immune system. ${ }^{22}$ Both phenotypes, the 'steroid' and the 'immune' phenotype, not only differ in terms of gene expression, but also regarding the prognosis.

In order to improve the understanding of the pathogenesis and prognostic of ACC, we focused on the interplay of steroid hormones and immune system to study the glucocorticoid-induced $\mathrm{T}$ cell depletion. A more profound analysis of the differences between the 'steroid' and 'immune' ACC phenotype will allow us to improve therapeutic immunogenic strategies resulting in a prognostic and clinical profit especially with regard to the immunotherapy of the ACC patients.

\section{MATERIAL AND METHODS \\ Patients and tissues}

One hundred and forty-six tumor samples of 109 patients with ACC (107 primary tumors, 16 local recurrences and 23 metastases) were used for this study. In $43 \%$ of patients, autonomous glucocorticoid excess was diagnosed by means of pathological $1 \mathrm{mg}$ dexamethasone test (cortisol $>5 \mu \mathrm{g} / \mathrm{dL}$ ) in presence of suppressed adrenocorticotropic hormone (ACTH) (see table $1,{ }^{23}$ ). Completeness of surgical resection of the primary tumor was based on negative surgical, pathological and imaging reports for any remaining malignant tissue. The presence of recurrences or metastases was evaluated at the time of diagnosis and during follow-up visits by computer tomography of chest and abdomen at an interval of 3 to 6 months. Metastases were not restricted to any secondary site, but rather evenly distributed; abdomen $(n=7)$, bone $(n=2)$, liver $(n=4)$, lung $(n=6)$ and lymph nodes $(\mathrm{n}=4)$.

\section{Antibodies and chemicals}

Primary antibodies used for detecting human T lymphocytes were mouse anti-CD3, rabbit anti-CD4, rabbit anti-CD8, and mouse anti-FoxP3 (for details see online supplementary table S1). Secondary antibodies for the detection of the aforementioned immunoglobulins were Alexa Fluor 488 goat anti-mouse IgG and Alexa Fluor 555 goat anti-rabbit IgG.

\section{Fluorescence immunohistochemistry}

Intraoperatively obtained tumor specimens were formalin-fixed and paraffin-embedded and $2 \mu \mathrm{m}$ slices were mounted on microscope slides. De-paraffinization was performed twice in $100 \%$ xylene for $10 \mathrm{~min}$, followed by re-hydration with subsiding ethanol solutions $(100 \%$, $90 \%, 80 \%$ and $70 \%$ ) and an extensive washing step with distillated water. Antigen retrieval was performed with freshly prepared $10 \mathrm{mM}$ citric acid monohydrate buffer ( $\mathrm{pH}$ 6, adjusted with sodium hydroxide; Merck, Darmstadt, Germany) in a pressure cooker for $10 \mathrm{~min}$. After cooling down to room temperature (RT), slides were rinsed with distillated water and fresh phosphate buffered saline (PBS (Sigma); pH 7.4). In order to prevent unspecific binding of tissue proteins a/o antibodies, slides were incubated with $10 \%$ goat serum (EMD Millipore Corporation, Temecula, USA) and $1 \%$ bovine serum albumin (BSA, Sigma) in PBS for $30 \mathrm{~min}$ at RT and subsequently co-incubated with primary antibodies anti-CD3/ CD8 and anti-CD4/FoxP3 overnight at $4^{\circ} \mathrm{C}$ in a humidified chamber. Negative controls were performed using $1 \%$ BSA in PBS without antibody cocktail. Tissue slides were washed three times with PBS and subsequently incubated with secondary antibodies (anti-mouse conjugated Alexa Fluor 488 and anti-rabbit conjugated Alexa Fluor 555 ; online supplementary table $\mathrm{S} 1$ ). After 1 hour incubation at RT, slides were washed three times in PBS. Immediately, cell nuclei were counterstained with DAPI for $3 \mathrm{~min}$, washed and mounted with ProLong Gold Antifade (Thermo Fisher). Three human tonsils served as positive control for immunogenic staining.

\section{Microscopic analysis}

For analysis of immune infiltrates, high power fields (HPFs, 40x magnification objective) were chosen without relevant necrosis for photography with an Axiovert 135 microscope (Carl Zeiss). The quantification of positive tumor-infiltrating immune cells was performed manually using the Image J software (Wayne Rasband, National Institutes of Health, USA).

For each whole tumor section, two independent investigators analyzed all 10 selected HPFs. To identify specific staining of the cell membrane, each single photographed color channel per HPF was considered for cell counting and only cells showing specific antibody-mediated membrane/nucleus staining for the different subpopulations of $\mathrm{T}$ lymphocytes were characterized as positive. 


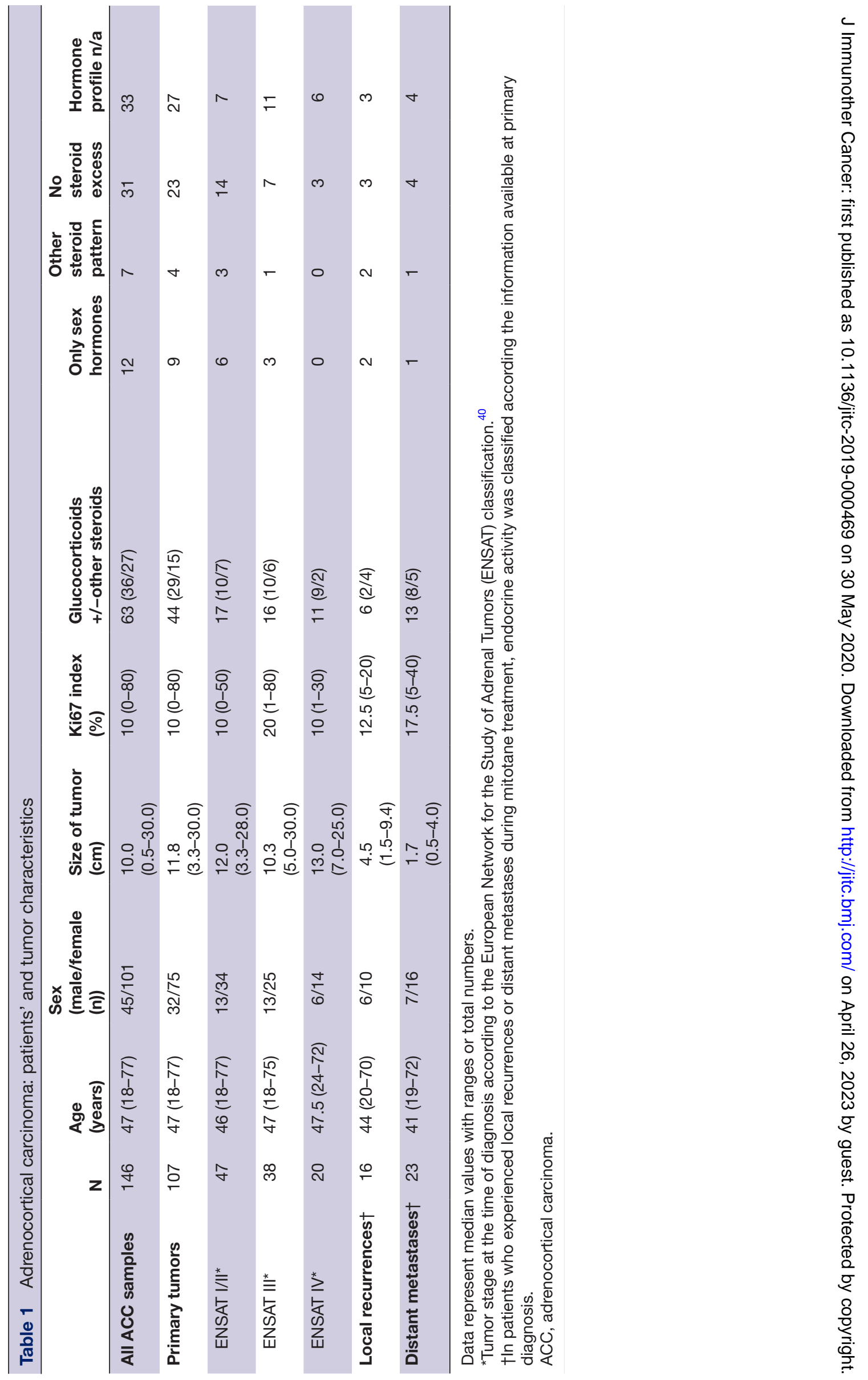




\section{Statistics}

Statistical analyzes were performed using Prism (V.5.0a, GraphPad Software Inc, La Jolla, California, USA) and SPSS (IBM Corporation, Armonk, New York, USA).

All statistically generated data were expressed as median and range; $p<0.05$ considered significance. Concerning the cut-off for tumor immune infiltration, absence of tumorous immune cell infiltration was termed 'negative', any infiltration of lymphocytes was 'positive'. Overall survival was the time interval from surgery to death or last follow-up, recurrence-free survival was defined as the period between surgery and the first occurrence of relapse. The Kaplan-Meier method and log-rank test was performed to estimate and compare event-free survival. Cox proportional hazards regression modeling was used for the identification of clinical factors that independently influence patients' survival. In a first step, for all known or potentially relevant prognostic factors (age, sex, autonomous glucocorticoid secretion, resection status, Ki67 proliferation index) a univariate analysis was performed. In addition, all different immune cell epitopes were analyzed independently due to their subtype character (marked by dashed line, table 2A+B). Hazard ratio (HR) with $95 \%$ CIs were evaluated by Cox regression as well. For the multivariate analysis, we then exclusively included parameters that had a significant impact on patients' prognosis and survival in the univariate analyzes.

For differences in tumor infiltration depending on tumor site and glucocorticoid excess, the t-test, an unpaired non-parametric Mann-Whitney test with median values with $95 \% \mathrm{CI}$, was performed; whereas, for per sample analyzes, a non-parametric Wilcoxon matched-pairs signed-rank test was used. Correlations between different variables was performed with Pearson's chi-squared test with Phi coefficient as a measure for effect size.

\section{RESULTS}

\section{ACC-infiltrating immune cells in primary tumors, local recurrences and metastases}

Using immunofluorescence microscopy, an infiltration of $\mathrm{CD}^{+} \mathrm{T}$ cells was detectable in $86 \%$ of the 146 ACC samples, but the median number of these cells was rather low $(7.7$ cells/HPF; figure $1 \mathrm{~A})$. We visualized $\mathrm{CD}^{+} \mathrm{CD}^{+}$ $\mathrm{T}$ helper cells in $74 \%$ of the ACC samples (figure 1B), while $\mathrm{CD}^{+} \mathrm{CD}^{+}$cytotoxic $\mathrm{T}$ lymphocytes were the most frequent infiltrating cell type (84\%, figure $1 \mathrm{C})$. In contrast, only $49 \%$ of the tumors were positive for $\mathrm{CD}^{+} \mathrm{C}^{-}$ $\mathrm{D}^{+}{ }^{+} \mathrm{FoxP}^{+}$regulatory T cells (figure 1D). Detailed results of the quantification of ACC-infiltrating $\mathrm{T}$ cells are given in online supplementary table S2.

We further analyzed potential differences in TILs between primary tumors, local recurrences and metastases. Primary ACC tumors $(\mathrm{n}=107)$ in comparison to metastases $(n=23)$ showed a trend of higher median number of $\mathrm{CD}^{+}-(8.5$ vs. 5.4 per $\mathrm{HPF})$ as well as $\mathrm{CD}^{+} \mathrm{CD}^{+}{ }^{+}$and $\mathrm{CD}^{+} \mathrm{CD}^{+}{ }^{+} \mathrm{T}$ cells (figure $2 \mathrm{~A}-\mathrm{C}$, online supplementary table S2). Of note, local tumors of stage IV ACC were infiltrated the most by TILs. They showed the highest median infiltration of $\mathrm{CD}^{+}-, \mathrm{CD}^{+} \mathrm{CD}^{+}{ }_{-}^{-}$ and $\mathrm{CD}^{+} \mathrm{CD}^{+} \mathrm{T}$ cells of $19.2,14.4$ and 8.2 cells per HPF, respectively. In addition, local recurrences are frequently infiltrated $(87.5 \%)$, even if $5.1 \mathrm{CD}^{+-}, 5.0 \mathrm{CD}^{+} \mathrm{CD}^{+}-$and 5.0 $\mathrm{CD}^{+} \mathrm{CD}^{+} \mathrm{T}$ cells per HPF are comparatively low (online supplementary table S2).

For a more detailed picture, a longitudinal analysis was performed in 14 patients, in whom both primary tumors and distant metastases were available. In agreement with the above-mentioned results, $\mathrm{T}$ cell infiltration was significantly lower in metastases compared with matched primary tumors. For both $\mathrm{CD}^{+}-$and $\mathrm{CD}^{+} \mathrm{CD} 4^{+} \mathrm{T}$ cells, a clear decline of immune cells was detectable in 12 of 14 patients and for $\mathrm{CD}^{+} \mathrm{CD}^{+} \mathrm{T}$ cells, the same trend was seen in all but one single patient (figure 2, D-F). Accordingly, the median number of $\mathrm{CD}^{+}-, \mathrm{CD}^{+} \mathrm{CD}^{+}-$, and $\mathrm{CD}^{+} \mathrm{CD}^{+} \mathrm{T}$ cells were higher in primary tumors $(4.5$, 4.7 and 4.4 cells per HPF, respectively) than in metastases (2.15, 1.15 and 2.0 cells per HPF, respectively).

\section{Overall and progression-free survival is associated with the presence of tumor-infiltrating immune cells}

To evaluate the impact of TILs on ACG patient survival, we first investigated overall survival in all 107 patients with available primary tumor samples by using univariate analyzes. The presence of ACC-infiltrating T lymphocytes was significantly associated with better overall survival in comparison to non-infiltrated ACC (figure 3A-C, table 2A). More precisely, ACC patients with a primary tumor with $\mathrm{CD}^{+} \mathrm{T}$ cell infiltration showed a median survival of 81.8 months, whereas in the absence of $\mathrm{CD}^{+}$ TILs the median survival was only 29.7 months (figure 3, table 2A). Similar results were seen for $\mathrm{CD}^{+} \mathrm{CD}^{+}-$and $\mathrm{CD}^{+} \mathrm{CD}^{+}$cytotoxic $\mathrm{T}$ cell infiltrated tumors with a median overall survival of 91.4 vs. 27.0 and 81.8 vs. 21.0 months, respectively (figure $3 \mathrm{~B}+\mathrm{C}$, table $2 \mathrm{~A}$ ). In contrast, in our series, was no significant association of $\mathrm{CD}^{+} \mathrm{CD}^{+-}$ $\mathrm{FoxP}^{+}$regulatory $\mathrm{T}$ cell infiltration and overall survival (table 2A).

Multivariate overall survival analyzes, including other potential prognostic factors, European Network for the Study of Adrenal Tumors (ENSAT) stage, resection status and Ki67 proliferation index, we confirmed a significant independent association of TILs only in patients with localized, non-metastatic tumors, whereas this effect was diminished when all patients (including those with metastatic disease) were analyzed (figure 3G-I, table 2A). However, in localized tumors, this effect was very strong for both, $\mathrm{CD}^{+} \mathrm{CD}^{+}-$and $\mathrm{CD}^{+} \mathrm{CD}^{+} \mathrm{T}$ cells with a threefold mortality risk reduction (HR $0.3,95 \%$ CI 0.13 to 0.66 and HR $0.29,95 \%$ CI 0.11 to 0.81 , respectively; figure $3 \mathrm{G}-\mathrm{I}$, table $2 \mathrm{~A}$ ).

Subsequently, to investigate the influence of TILs on recurrence-free survival, we focused on a subgroup of ACC patients with primary localized, non-metastatic tumors after complete surgical resection $(n=59)$. Similarly 


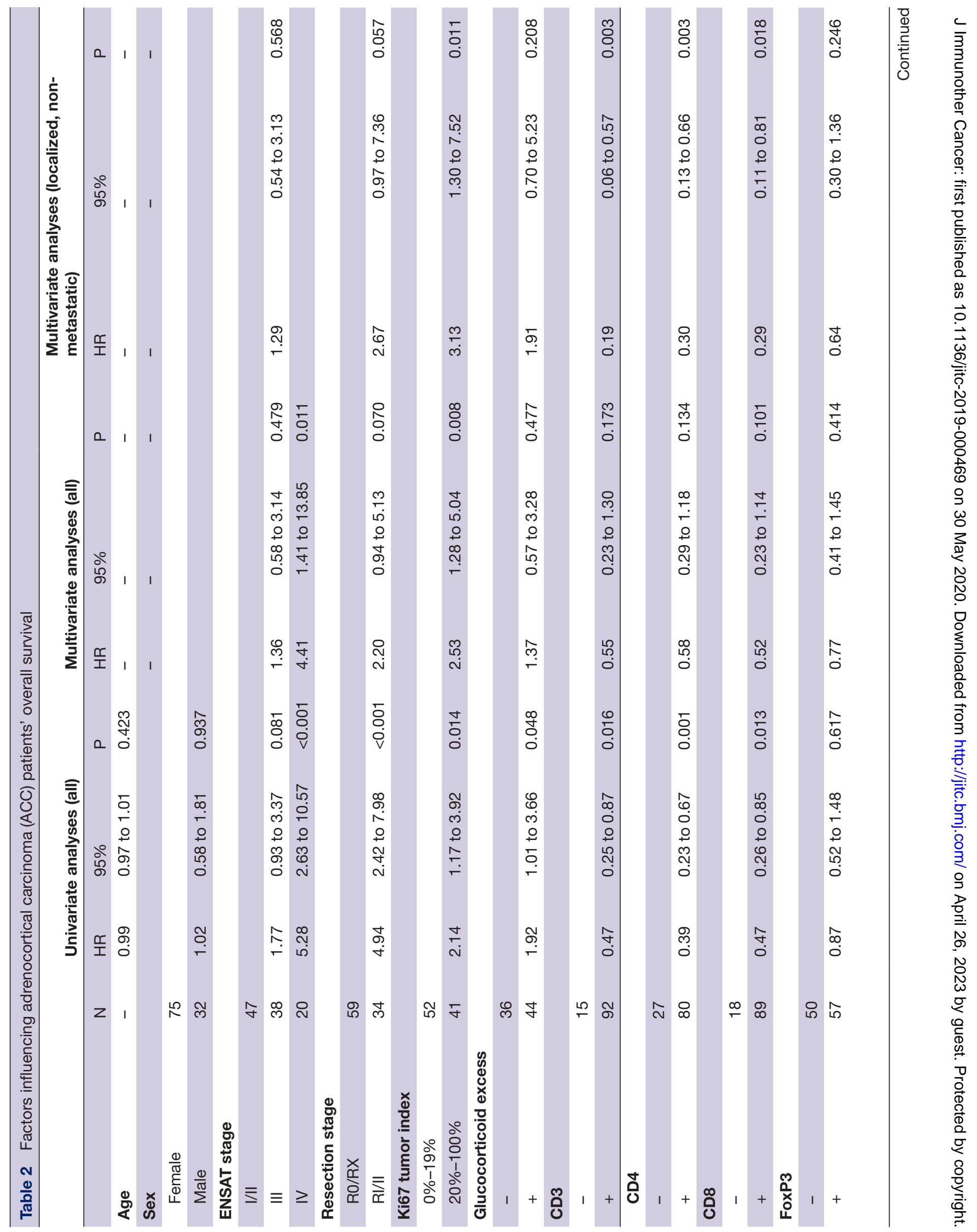




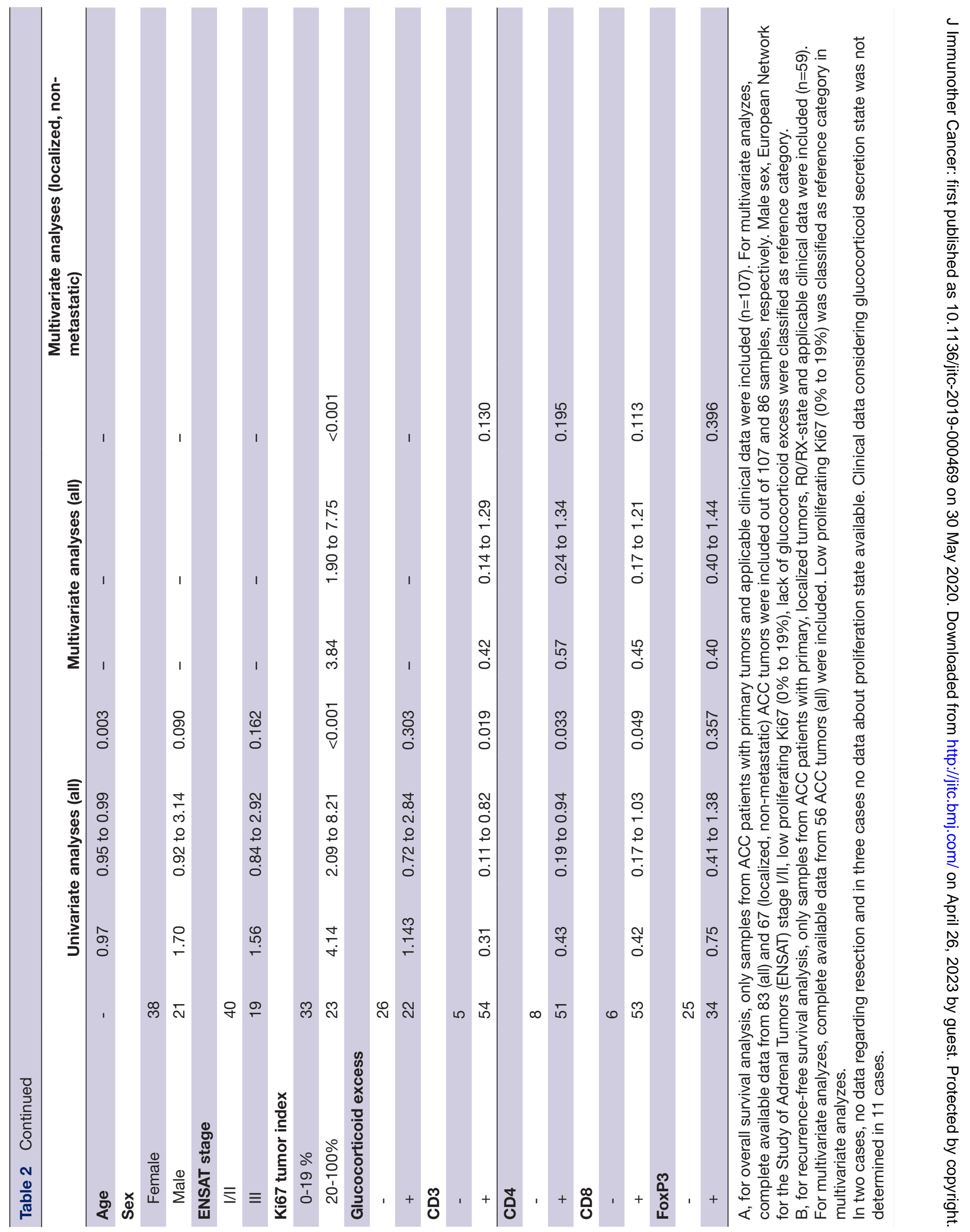



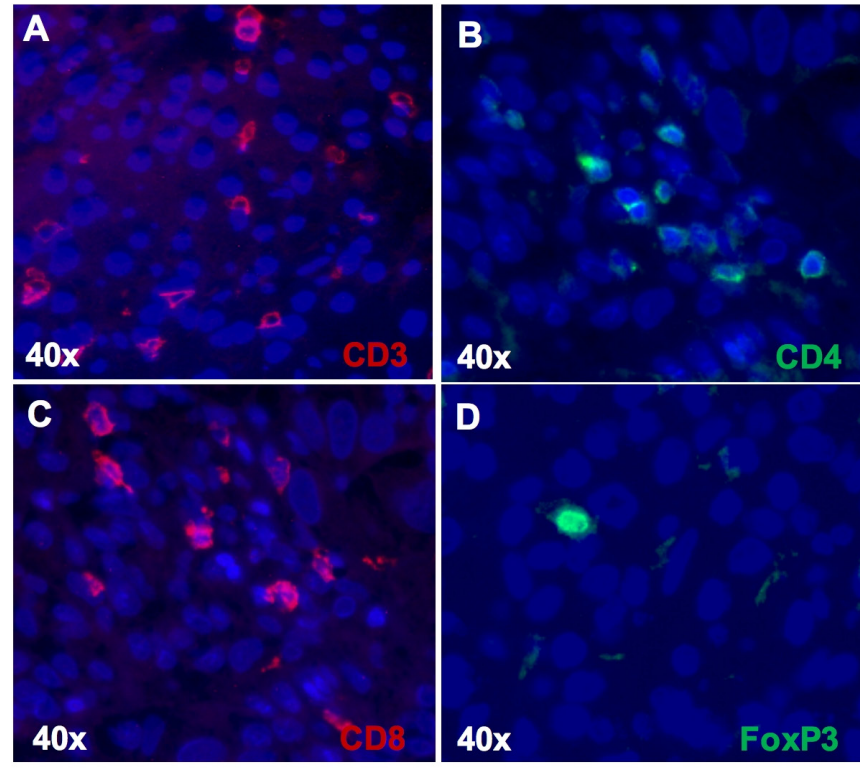

D

FoxP3

Immune Cells

$\%$ of $\mathrm{ACC}$

$\mathrm{n}$ of TILs/HPF

\begin{tabular}{|ccc|}
\hline CD3 & $86.3 \%$ & $7.7(0.1-376.0)$ \\
\hline CD4 & $74.0 \%$ & $6.7(0.2-109.0)$ \\
\hline CD8 & $84.3 \%$ & $5.7(0.1-291.0)$ \\
\hline FoxP3 & $49.3 \%$ & $0.8(0.1-18.0)$ \\
\hline
\end{tabular}

Figure 1 Immunofluorescence staining of tumor-infiltrating lymphocytes in adrenocortical carcinoma, $n=146,(A-D)$. ACC,adrenocortical carcinoma; HPF, high power field; TILs, tumor-infiltrating $\mathrm{T}$ lymphocytes.

to the results on overall survival, $\mathrm{CD}^{+}-, \mathrm{CD}^{+} \mathrm{CD} 4^{+}-$ and $\mathrm{CD}^{+} \mathrm{CD}^{+}$TILs were associated with a significantly longer median recurrence-free survival (24.2 vs. 10.7 months, 25.5 vs. 10.7 months and 24.2 vs 10.7 months, respectively; figure 3D-F, table $2 \mathrm{~B}$ ). However, in multivariate analysis including Ki67 index these effects lost significance (table 2B).

\section{Influence of glucocorticoids on tumor-infiltrating lymphocytes}

In order to investigate the immunosuppressive effect of glucocorticoids on T cells, the presence of TILs in primary ACC samples and tumor-induced autonomous cortisol excess were correlated using Pearson correlation coefficient. Of note, among all $\mathrm{T}$ cell subtypes analyzed, only $\mathrm{CD}^{+} \mathrm{CD}^{+}$TILs showed a significant negative correlation with glucocorticoids in patients with ACC ( $\mathrm{Phi}=-0.290$, $\mathrm{p}=0.009$; figure 4 , online supplementary table S3. The number of $\mathrm{CD}^{+} \mathrm{CD} 4^{+}$TILs was significantly higher in ACC without glucocorticoid excess (median 7.7 vs. 1.8 cells per HPF; figure 4A). 32 out of 36 primary tumor samples $(89 \%)$ from patients without glucocorticoid excess had $\mathrm{CD}^{+} \mathrm{CD}^{+} \mathrm{T}$ cell tumor infiltration, whereas this occurred in only $64 \%$ of cases with hypercortisolism. In line with this, $80 \%$ of the $\mathrm{CD}^{+} \mathrm{CD}^{+}{ }^{+} \mathrm{T}$ cell-depleted ACC were detected in patients with glucocorticoid excess. Similar results were observed focusing on the entire cohort including local recurrences and metastases (Phi $=-0.260, \mathrm{p}=0.006$; online supplementary table S3).

At last, we performed overall survival analyzes considering not only immune infiltration, but also ACC-induced hypercortisolism. This resulted in a more refined prognostication with four subgroups (figure 4B). Tumors with $\mathrm{CD}^{+} \mathrm{CD}^{+} \mathrm{T}$ cell infiltration and without glucocorticoid excess exhibited the most favorable overall survival with a median of 121.0 months, followed by ACC tumors with presence of infiltrated immune cells and glucocorticoid excess (median overall survival: 75.0 months). The prognosis of the lymphocyte-depleted tumors was clearly worse and again glucocorticoid dependent (median overall survival without hypercortisolism: 44.9 months vs. 27.0 months with cortisol excess). This implies a 1.44 and 3.82 times higher risk for death with excessive glucocorticoid secretion in $\mathrm{CD}^{+} \mathrm{CD} 4^{+} \mathrm{T}$ cell-infiltrated and $\mathrm{T}$ cell-depleted ACC in comparison to $\mathrm{CD}^{+} \mathrm{CD} 4^{+} \mathrm{T}$ cellinfiltrated and hormone inactive tumors, respectively (figure 4B).

\section{DISCUSSION}

In this first large study on immune cell infiltration in ACC, we demonstrated a significant impact of $\mathrm{CD}^{+}{ }^{+}$, $\mathrm{CD}^{+} \mathrm{CD}^{+}-$and $\mathrm{CD}^{+} \mathrm{CD}^{+}$TILs on clinical outcome. In particular, in localized, non-metastatic ACC the effect of TILs on overall survival was independent of clinically relevant factors, like ENSAT stage, resection status and Ki67 index and remarkably with a relative risk reduction of about $70 \%$. Additionally, our study suggests a relevant influence of tumor-induced glucocorticoids on intratumorous $\mathrm{CD} 3^{+} \mathrm{CD}^{+} \mathrm{T}$ cells and overall prognosis.

Since $\mathrm{CD}^{+} \mathrm{CD}^{+}-$and $\mathrm{CD}^{+} \mathrm{CD}^{+} \mathrm{T}$ cells are powerful assistants in preventing and combating cancer, their presence in the tumor microenvironment and within the tumor mass is crucial. The fraction of lymphocytes infiltrated within tumors varied considerably across tumor types and depends on different factors. Highly immune infiltrated tumors like lung adenocarcinoma and cutaneous melanoma are highly responsive to immune checkpoint therapies. ${ }^{24}$ In contrast, ACC is after uveal melanoma and prostate adenocarcinoma the tumor with the lowest leukocyte fraction according to Thorsson et al, who analyzed the composition of tumor immune infiltration within the TCGA cohort on the level of RNA expression. ${ }^{24}$

Here, we quantified $\mathrm{CD}^{+}-, \mathrm{CD}^{+} \mathrm{CD}^{+}-, \mathrm{CD}^{+} \mathrm{CD}^{+}-$ and $\mathrm{CD}^{+}{ }^{+} \mathrm{CD} 4^{+} \mathrm{FoxP}^{+}$TILs in a cohort of 146 ACC patients and studied the influence of their presence on patients' survival. Thereby, we provided evidence thatin contrast to a widespread perception-the majority of ACC samples $(>85 \%)$ contained tumor-infiltrating $\mathrm{T}$ lymphocytes; as recently shown in childhood ACC. ${ }^{25}$ However, we have to acknowledge that the number of TILs is rather low in comparison to other tumors. ${ }^{26} 27$ Nevertheless, we could demonstrate a significant impact 

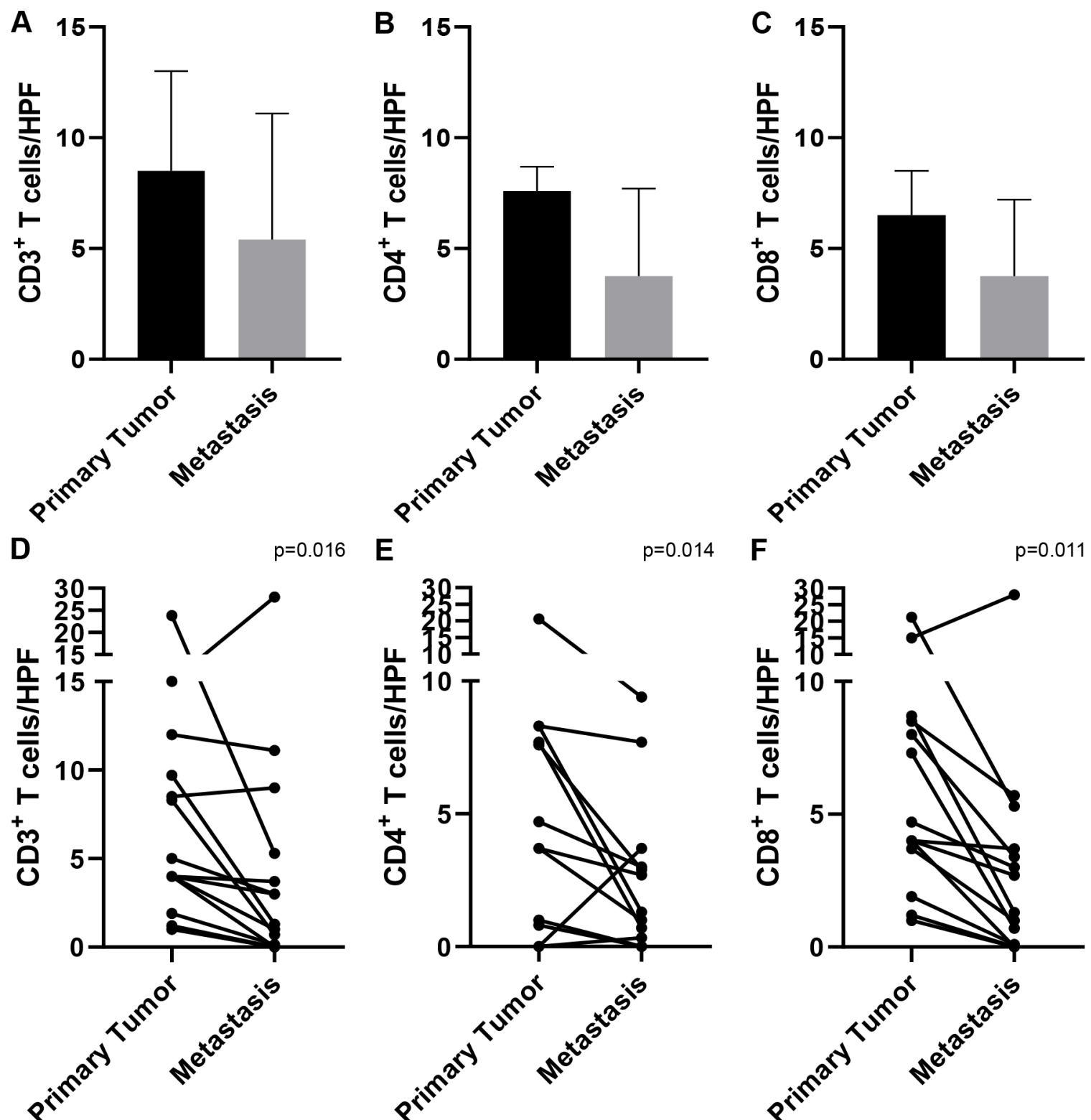

Figure 2 Comparison of tumor-infiltrating lymphocytes in primary tumors and metastases of ACC (median $95 \% \mathrm{Cl}$ ). A-C, $\mathrm{CD}^{+}-(\mathrm{A}), \mathrm{CD}^{+}-(\mathrm{B})$ and $\mathrm{CD}^{+}-(\mathrm{C})$ T cells infiltrated in adrenocortical tumor samples from primary localized tumor tissue $(n=107)$ or distant metastases $(n=23)$ of entire cohort. Per sample analysis (D-F), CD3 ${ }^{+}-(D), C D 4^{+}-(E)$ and CD8 ${ }^{+}-(F) T^{2}$ cells quantified in primary tumor and metastasis of the same patient $(n=14)$. ACC,adrenocortical carcinoma; HPF, high power field.

of TILs on ACC patients' overall and recurrence-free survival. Many studies have shown the strong influence of TILs on patients' prognosis, also independently of the choice of treatment. For instance, Zhang et al demonstrated already in 2003 an improved clinical outcome in advanced ovarian carcinoma depending on the presence or absence of lymphocytes. Immune depleted ovarian tumors show a median progression-free survival of only 7.6 months, while intratumorous immune infiltration is associated with 74.5 months until recurrence. ${ }^{27} \mathrm{~A}$ similarly favorable impact of tumor infiltration on overall and recurrence-free survival was observed in the present study of ACC. Accordingly, $\mathrm{CD}^{+-}, \mathrm{CD}^{+} \mathrm{CD}^{+-}$and $\mathrm{CD}^{+} \mathrm{CD}^{+}$ TIL number was associated with a risk reduction of $53 \%$ to $61 \%$ for death and $57 \%$ to $69 \%$ for recurrence. In particular, TILs in localized, non-metastatic ACC may serve as a prognostic marker independently of clinically established factors, like ENSAT stage, resection status, and Ki67 index leading to a risk reduction for death of $70 \%$ to $81 \%$. Furthermore, our study indicates that TILs are even less frequent in metastatic lesions in comparison to primary tumors. Similar observations were made in other tumors like metastatic breast cancer that is characterized by lower immune cell infiltration relative to its paired primary tumor. ${ }^{28}$

Several clinical studies on immune checkpoint inhibitors (ICIs), which flare up antitumor immune responses, showed major therapeutic improvements in many tumor entities. The first approved cytotoxic T-lymphocytes antigen-4 (CTLA-4) inhibitor, ipilimumab, demonstrated 

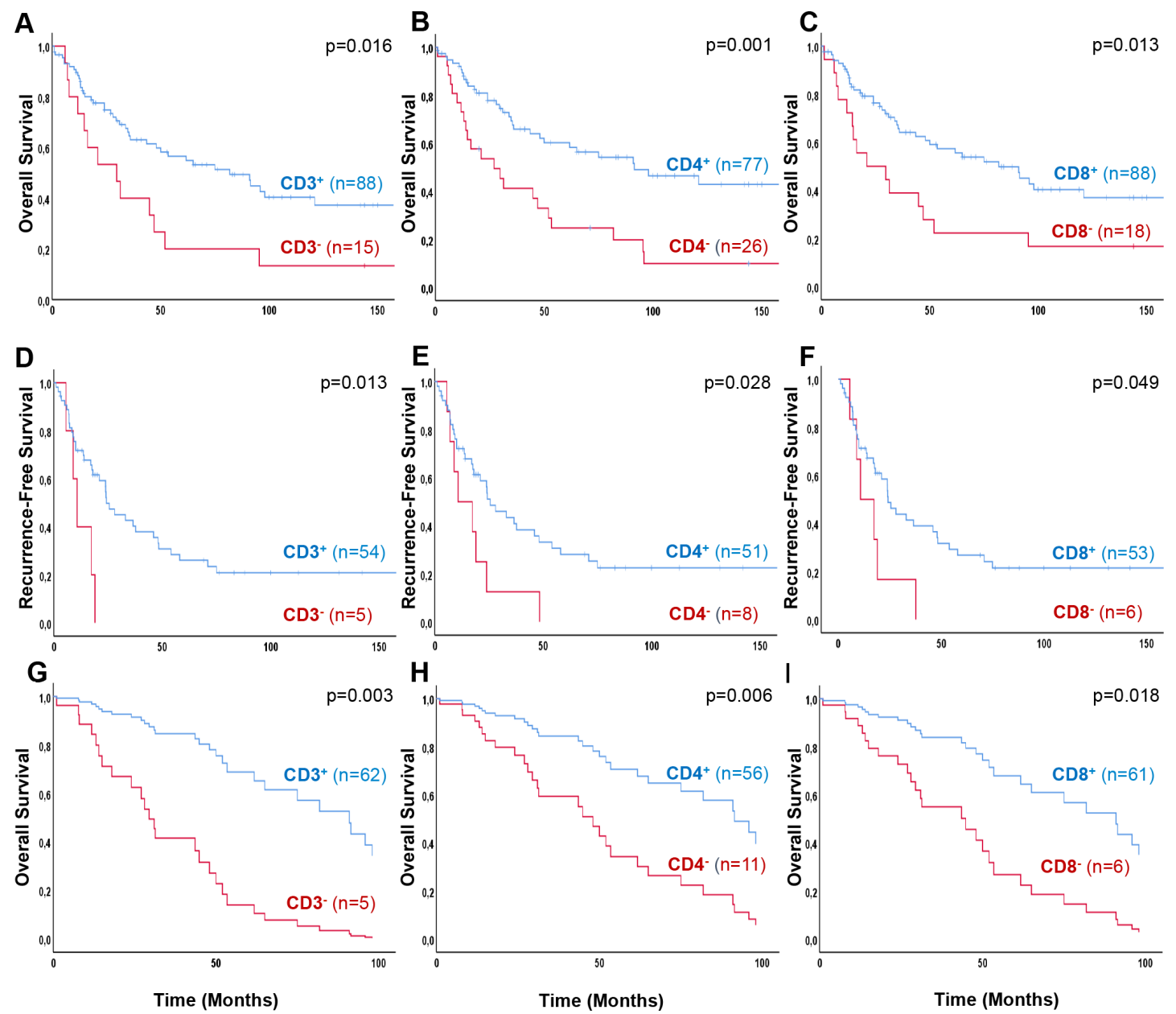

Figure 3 Overall survival $(A-C)$ and recurrence-free survival (D-F) in patients with adrenocortical carcinoma according to $\mathrm{CD}^{+}-, \mathrm{CD}^{+}-$and $\mathrm{CD} 8^{+}$TILs, determined by immunofluorescence. Kaplan-Meier overall survival of all ACC patients with primary tumor samples $(n=107)$ influenced by $\mathrm{CD}^{+}-(A), C D 4^{+}-(B)$ and $C D 8^{+}-(C)$ T cell infiltration. In a subgroup, patients after complete surgical resection and in localized ACC, a Kaplan-Meier recurrence-free survival analysis was performed regarding $\mathrm{CD}^{+}-(\mathrm{D}), \mathrm{CD}^{+}-(\mathrm{E})$ and $\mathrm{CD}^{+}-(\mathrm{F})$ tumor infiltration $(\mathrm{n}=59)$. Multivariate Cox regression, overall survival $(\mathrm{G}-\mathrm{l})$ in patients with localized, non-metastatic ACC according to different influencing factors; ENSAT stage, resection status, Ki67 proliferation index and TILs. Overall survival of all ACC patients with localized, non-metastatic primary tumor samples ( $n=67)$ influenced by $\mathrm{CD}^{+}-(\mathrm{G}), \mathrm{CD}^{+}-(\mathrm{H})$ and $\mathrm{CD}^{+}-(\mathrm{I}) \mathrm{T}$ cell infiltration independently of different factors. ACC,adrenocortical carcinoma; ENSAT, European Network for the Study of Adrenal Tumors; TILs, tumor-infiltrating T lymphocytes.

enormous success in advanced melanoma. ${ }^{29}$ Other ICIs targeting programmed cell death-1 (PD-1), nivolumab and pembrolizumab, exhibit very promising clinical benefit in non-small cell lung carcinoma, melanoma, Hodgkin's lymphoma, and other tumor entities; ${ }^{30-32}$ the combination of CTLA-4 and PD-1 targeting drugs is even more potent. ${ }^{31}$ However, so far, four small studies with a total of 115 patients have been published in ACC and overall the results were disappointing; only 15 patients experienced partial response and 12 long-term disease control for more than 12 months. ${ }^{7-10}$

Our study may shed some light, why strong immune infiltration is rarely seen in ACC and why current immunological therapeutic options were of limited efficacy. The fact that we found a negative correlation of tumorassociated glucocorticoid excess and $\mathrm{T}$ helper cells supports an expected role of steroids in this context. Antiinflammatory impact of glucocorticoids was especially observed towards $\mathrm{CD}^{+} \mathrm{CD} 4^{+}$TILs, which play a major role in immune activation and regulation of immune response. As indicated by our large cohort, ACC patients without hypercortisolism, but with $\mathrm{CD}^{+} \mathrm{CD}^{+}$TILs may benefit from a major survival advantage compared to patients with hypercortisolim with or-even more pronouncedly-without $\mathrm{CD}^{+} \mathrm{CD}^{+} \mathrm{T}$ cell infiltrated tumors (121 vs. 75 vs. 27 months). These observations might also explain why hypercortisolism has a significant effect on survival. ${ }^{11-13}$ In these patients, antitumorous immune response may be diminished which may lead to a higher rate of recurrence and ACC-related deaths.

It is well established that glucocorticoids execute antiinflammatory, pro-apoptotic effects and have a strong impact on multiple physiological processes, that is, cell differentiation, proliferation, migration and apoptosis. Furthermore, it has been shown that hypersecretion of glucocorticoids enhances tumor cell proliferation in vitro 

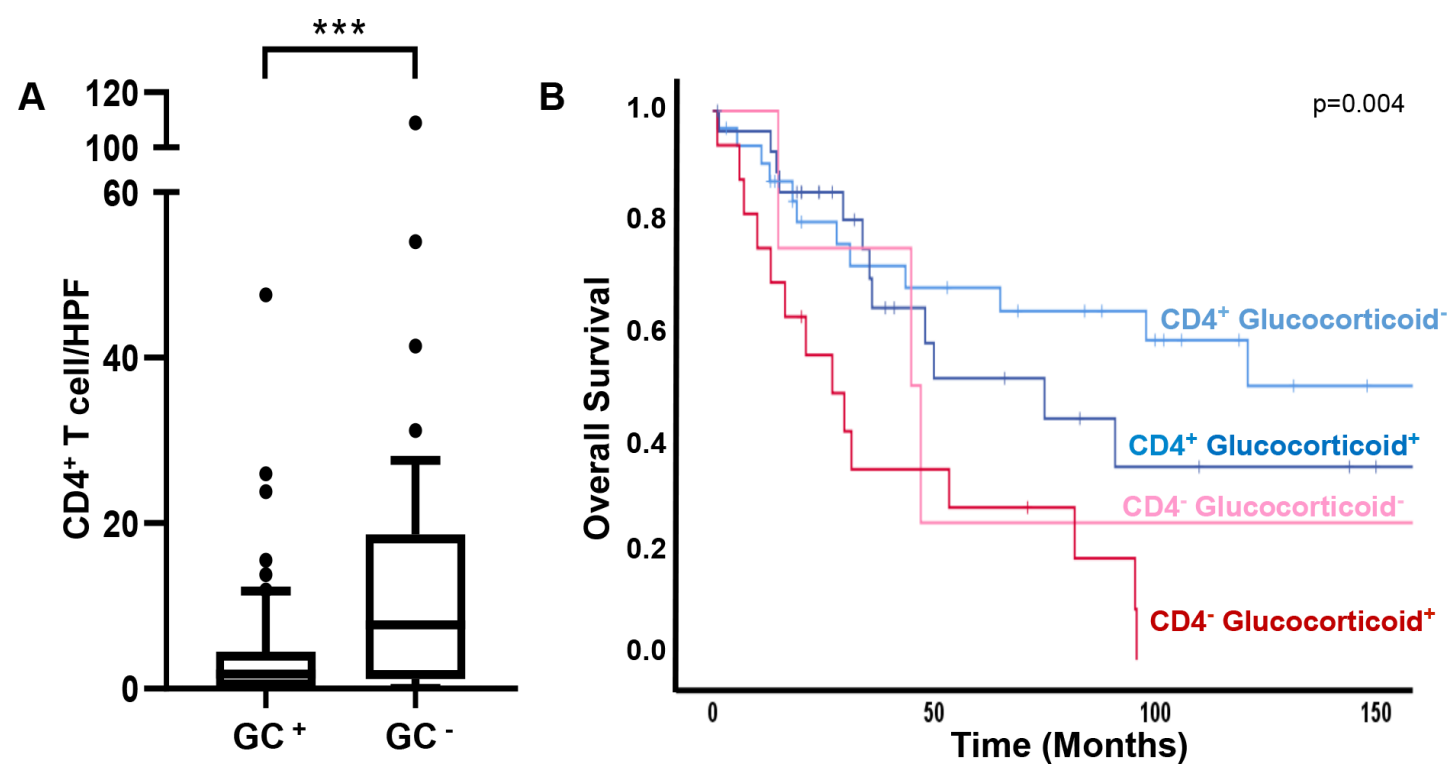

Figure 4 Correlation of glucocorticoids and $\mathrm{CD} 3^{+} \mathrm{CD} 4^{+} \mathrm{T}$ cells. (A) An unpaired non-parametric Mann-Whitney test was performed for correlation of the number of $\mathrm{CD} 3^{+} \mathrm{CD} 4^{+}$TILs with glucocorticoid excess or hormone inactive primary ACC (box/

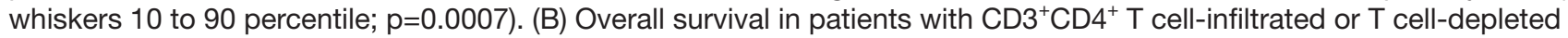
primary ACC considering presence or lack of glucocorticoid excess $(n=80)$. Primary tumors with available hormone secretion status were classified as 'lymphocytes-infiltrated' depending on positive immune infiltration (blue) and in case of absent tumor-infiltrating immune cells as 'lymphocytes-depleted' (red). Additionally, further subdivision of phenotypes according to glucocorticoid excess or hormonal inactivity. ACC,adrenocortical carcinoma; HPF, high power field; TILs, tumor-infiltrating Tlymphocytes.

and in vivo. ${ }^{33}$ Additionally, glucocorticoids also hamper peripheral T lymphocyte function, reducing their potential to eradicate tumor cells in the case of active ACC. The tumor-associated elevation of glucocorticoids has been observed in many cancers and associated with impaired prognosis and metastatic spread. For instance, in renal cell carcinoma, high levels of serum cortisol were positively correlated with tumor size and impaired prognosis. ${ }^{34}$ Inversely, a study concerning optimal application of steroids in anticancer therapy showed glucocorticoids to enhance tumorous PD-1 expression resulting in immune evasion. ${ }^{35}$ Thus, ACC-induced hypercortisolism might be a major contributor to the 'immunological coldness' of ACC. ${ }^{36}$

Our study might provide at least three potential explanations for the disappointing results of the first trials with

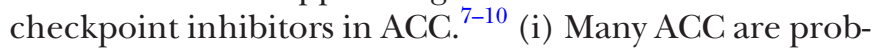
ably infiltrated by too few or no helper and cytotoxic $\mathrm{T}$ cells that would allow flaring up an antitumor response by checkpoint inhibitors. (ii) The fact that metastatic lesions are in average even 'colder' than the primary tumors suggests that immune escape mechanisms are even more developed in advanced ACC increasing the challenge for immunotherapies. ${ }^{36}$ (iii) The likelihood that glucocorticoids are-at least in part-responsible for the poor immunogenicity is high and further supported by the demonstrated negative correlation of hypercortisolism and T helper cells in ACC. However, one has to bear in mind that intratumorous glucocorticoid concentrations might be also much higher in clinically non-functioning
ACC (without systemically measurable cortisol levels) in comparison to other solid tumors.

The main limitations of our study are the relatively low number of patients and tumor samples, especially of metastatic material compared with other tumor entities. However, the extraordinary rarity of ACC renders the collection of a larger series of clinically annotated cases. This retrospective nature of the study made the availability of certain clinical data challenging.

It might also be interesting to correlate TILs and glucocorticoid excess in a quantitative manner or with intratumorous steroid excess. However, this requires also a prospective approach.

Our study has several clinical implications: It is obvious that future immunotherapy trials in ACC require selection of patients. In addition to parameters like PD-1/ PD-L1 (programmed cell death-ligand-1) expression or tumor mutational burden, the presence of TILs could be a promising predictive marker that should be explored. Instead of analyzing primary tumor samples, metastatic lesions could be the better and more reliable context. In addition, it is most likely useful to reduce the effect of glucocorticoids by inhibiting steroidogenesis ${ }^{37}$ or blocking glucocorticoid receptors. ${ }^{38}$ Failure to reduce the intratumorous immune suppressive potential of glucocorticoids, even lead to inefficacy of immunotherapy in ACC without detectable cortisol excess. Finally, adoption of concepts investigated in other tumor entities to transform 'cold' tumors in 'hot' tumors ${ }^{36} 39$ are probably required in addition to the measures mentioned above. 
In conclusion, tumor-infiltrating $\mathrm{CD}^{+}-, \mathrm{CD}^{+} \mathrm{CD}^{+}{ }_{-}^{-}$ and $\mathrm{CD}^{+} \mathrm{CD}^{+} \mathrm{T}$ cells are of major prognostic and clinical relevance in ACC patients. In addition, the interplay of glucocorticoids and immune cells are most likely crucial for ACC patients' survival. Consequently, a combined therapy of at least immune activating approaches and blockers of glucocorticoid synthesis or action might be required to improve clinical outcome in ACC. However, this hypothesis requires prospective investigations.

Twitter Laura-Sophie Landwehr @endo_wue

Acknowledgements This study was enabled through the continuous support in sample collection and preparation by Sonja Gommersbach and Martina Zink. Additionally, we are thankful for constant and precise collection and documentation of clinical data from Michaela Haaf and Cristina L Ronchi.

Contributors Conceptualization: MK, MF and SS; Methodology: LL, BA, JS, IS and IW; Formal analysis: LL, BA and SS; Resources: MK, MF and SS; Data curation: LL and BA; Writing-original draft preparation: $\mathrm{LL}, \mathrm{MK}, \mathrm{MF}$ and SS; Writing-review and editing: LL, BA, JS, IS, IW, MK, MF and SS; Visualization: LL and IW; Supervision: MK, MF and SS; Funding acquisition: MK, MF and SS.

Funding This study was funded by the German Research Foundation (Deutsche Forschungsgemeinschaft (DFG); project numbers: 314061271 - CRC/TRR 205 to MF and MK and FA-466-4-2 to MF and KR4371/1-2 to MK), and by the Else KrönerFresenius Foundation (Else Kröner-Fresenius Stiftung (EKFS); project number: 2016 A96 to SS and MK). Part of publication costs were supported by the Open Access Publication Fund of the University of Würzburg.

Competing interests None declared.

Patient consent for publication This manuscript does not contain personal and/or medical information about an identifiable living individual. All anonymous patients provided a written informed consent.

Ethics approval The study was conducted as part of the European Network for the Study of Adrenal Tumors (ENSAT) ACC Registry, conformed to the principles of the Declaration of Helsinki, the Good Clinical Practice Guidelines and was approved by the ethics committee of the University of Würzburg (\#88/11). All patients provided a written informed consent for collecting tissue and clinical data, including follow-up and survival data. Control tissues (three non-pathological tonsils) were provided by the tissue biobank of the Institute of Pathology of the University of Würzburg and were analyzed in an anonymous fashion. This manuscript does not contain personal and/or medical information about an identifiable living individual.

Provenance and peer review Not commissioned; externally peer reviewed.

Data availability statement All data relevant to the study are included in the article or uploaded as supplementary information.

Open access This is an open access article distributed in accordance with the Creative Commons Attribution Non Commercial (CC BY-NC 4.0) license, which permits others to distribute, remix, adapt, build upon this work non-commercially, and license their derivative works on different terms, provided the original work is properly cited, appropriate credit is given, any changes made indicated, and the use is non-commercial. See http://creativecommons.org/licenses/by-nc/4.0/.

\section{ORCID iDs}

Laura-Sophie Landwehr http://orcid.org/0000-0002-6315-4176

Barbara Altieri http://orcid.org/0000-0003-2616-3249

Isabel Weigand http://orcid.org/0000-0001-5873-8567

Matthias Kroiss http://orcid.org/0000-0002-7628-316

Martin Fassnacht http://orcid.org/0000-0001-6170-6398

Silviu Sbiera http://orcid.org/0000-0002-6271-5533

\section{REFERENCES}

1 Else T, Kim AC, Sabolch A, et al. Adrenocortical carcinoma. Endocr Rev 2014;35:282-326.

2 Fassnacht M, Dekkers O, Else T, et al. European Society of endocrinology clinical practice guidelines on the management of adrenocortical carcinoma in adults, in collaboration with the European network for the study of adrenal tumors. Eur $J$ Endocrinol 2018;179:G1-46.
3 Fassnacht M, Terzolo M, Allolio B, et al. Combination chemotherapy in advanced adrenocortical carcinoma. $N$ Engl J Med 2012;366:2189-97.

4 Megerle F, Herrmann W, Schloetelburg W, et al. Mitotane monotherapy in patients with advanced adrenocortical carcinoma. $J$ Clin Endocrinol Metab 2018;103:1686-95.

5 Ayala-Ramirez M, Jasim S, Feng L, et al. Adrenocortical carcinoma: clinical outcomes and prognosis of 330 patients at a tertiary care center. Eur J Endocrinol 2013;169:891-9.

6 Megerle F, Kroiss M, Hahner S, et al. Advanced Adrenocortical Carcinoma - What to do when First-Line Therapy Fails? Exp Clin Endocrinol Diabetes 2019;127:109-16.

7 Carneiro BA, Konda B, Costa RB, et al. Nivolumab in metastatic adrenocortical carcinoma: results of a phase 2 trial. $J$ Clin Endocrinol Metab 2019;104:6193-200.

8 Raj N, Zheng Y, Kelly V, et al. Pd-1 blockade in advanced adrenocortical carcinoma. J Clin Oncol 2020;38:JC01901586.:71-80.

9 Le Tourneau C, Hoimes C, Zarwan C, et al. Avelumab in patients with previously treated metastatic adrenocortical carcinoma: phase $1 \mathrm{~B}$ results from the javelin solid tumor trial. $J$ Immunother Cancer 2018;6:111

10 Habra MA, Stephen B, Campbell M, et al. Phase II clinical trial of pembrolizumab efficacy and safety in advanced adrenocortical carcinoma. J Immunother Cancer 2019;7:253.

11 Berruti A, Fassnacht M, Haak H, et al. Prognostic role of overt hypercortisolism in completely operated patients with adrenocortical cancer. Eur Urol 2014;65:832-8.

12 Fassnacht M, Kroiss M, Allolio B. Update in adrenocortical carcinoma. J Clin Endocrinol Metab 2013;98:4551-64.

13 Vanbrabant T, Fassnacht M, Assie G, et al. Influence of hormonal functional status on survival in adrenocortical carcinoma: systematic review and meta-analysis. Eur J Endocrinol 2018;179:429-36.

14 Coutinho AE, Chapman KE. The anti-inflammatory and immunosuppressive effects of glucocorticoids, recent developments and mechanistic insights. Mol Cell Endocrinol 2011;335:2-13.

15 Ossendorp F, Mengedé E, Camps M, et al. Specific T helper cell requirement for optimal induction of cytotoxic $T$ lymphocytes against major histocompatibility complex class II negative tumors. J Exp Med 1998; 187:693-702.

16 Hwu P. Treating cancer by targeting the immune system. N Engl J Med 2010;363:779-81.

17 Tan W-L, Jain A, Takano A, et al. Novel therapeutic targets on the horizon for lung cancer. Lancet Oncol 2016;17:e347-62.

18 Schreiber RD, Old LJ, Smyth MJ. Cancer immunoediting: integrating immunity's roles in cancer suppression and promotion. Science 2011;331:1565-70.

19 Curiel TJ, Coukos G, Zou L, et al. Specific recruitment of regulatory $T$ cells in ovarian carcinoma fosters immune privilege and predicts reduced survival. Nat Med 2004;10:942-9.

20 Bates GJ, Fox SB, Han C, et al. Quantification of regulatory T cells enables the identification of high-risk breast cancer patients and those at risk of late relapse. J Clin Oncol 2006;24:5373-80.

21 Badoual C, Hans S, Rodriguez J, et al. Prognostic value of tumorinfiltrating CD4+ T-cell subpopulations in head and neck cancers. Clin Cancer Res 2006;12:465-72.

22 Zheng S, Cherniack AD, Dewal N, et al. Comprehensive pangenomic characterization of adrenocortical carcinoma. Cancer Cell 2016;30:363.

23 Fassnacht M, Arlt W, Bancos I, et al. Management of adrenal incidentalomas: European Society of endocrinology clinical practice guideline in collaboration with the European network for the study of adrenal tumors. Eur J Endocrinol 2016;175:G1-34.

24 Thorsson V, Gibbs DL, Brown SD, et al. The immune landscape of cancer. Immunity 2018;48:e14.:812-30.

25 Parise IZS, Parise GA, Noronha L, et al. The prognostic role of CD8. Cancers 2019;11.

26 Eerola AK, Soini Y, Pääkkö P. A high number of tumor-infiltrating lymphocytes are associated with a small tumor size, low tumor stage, and a favorable prognosis in operated small cell lung carcinoma. Clin Cancer Res 2000;6:1875-81.

27 Zhang L, Conejo-Garcia JR, Katsaros D, et al. Intratumoral T cells, recurrence, and survival in epithelial ovarian cancer. $N$ Engl $J$ Med 2003;348:203-13.

28 Zhu L, Narloch JL, Onkar S, et al. Metastatic breast cancers have reduced immune cell recruitment but harbor increased macrophages relative to their matched primary tumors. J Immunother Cancer 2019;7:265.

29 Hodi FS, O'Day SJ, McDermott DF, et al. Improved survival with ipilimumab in patients with metastatic melanoma. N Engl $\mathrm{J}$ Med 2010;363:711-23. 
30 Borghaei H, Paz-Ares L, Horn L, et al. Nivolumab versus docetaxel in advanced Nonsquamous non-small-cell lung cancer. N Engl J Med 2015;373:1627-39.

31 Larkin J, Chiarion-Sileni V, Gonzalez R, Hodi FS, Wolchok JD, et al. Combined nivolumab and ipilimumab or monotherapy in untreated melanoma. N Engl J Med 2015;373:23-34.

32 Chen R, Zinzani PL, Fanale MA, et al. Phase II study of the efficacy and safety of pembrolizumab for relapsed/refractory classic Hodgkin Iymphoma. J Clin Oncol 2017;35:2125-32.

33 Gündisch S, Boeckeler E, Behrends U, et al. Glucocorticoids augment survival and proliferation of tumor cells. Anticancer Res 2012;32:4251-61.

34 Rasmuson T, Ljungberg B, Grankvist K, et al. Increased serum cortisol levels are associated with high tumour grade in patients with renal cell carcinoma. Acta Oncol 2001;40:83-7.

35 Xing K, Gu B, Zhang P, et al. Dexamethasone enhances programmed cell death 1 (PD-1) expression during $T$ cell activation: an insight into the optimum application of glucocorticoids in anti-cancer therapy. BMC Immunol 2015;16:39.

36 Bonaventura P, Shekarian T, Alcazer V, et al. Cold tumors: a therapeutic challenge for immunotherapy. Front Immunol 2019;10:168.

37 Daniel E, Newell-Price JDC. Therapy of endocrine disease: steroidogenesis enzyme inhibitors in Cushing's syndrome. Eur J Endocrinol 2015;172:R263-80.

38 Fleseriu M, Biller BMK, Findling JW, et al. Mifepristone, a glucocorticoid receptor antagonist, produces clinical and metabolic benefits in patients with Cushing's syndrome. J Clin Endocrinol Metab 2012;97:2039-49.

39 Chen DS, Mellman I. Oncology meets immunology: the cancerimmunity cycle. Immunity 2013;39:1-10.

40 Fassnacht M, Johanssen S, Quinkler M, et al. Limited prognostic value of the 2004 International Union against cancer staging classification for adrenocortical carcinoma: proposal for a revised TNM classification. Cancer 2009;115:243-50. 